\title{
Assessment of environmental sustainability in renal healthcare
}

\author{
Kei Nagai ${ }^{1}$, Hiroaki Suzuki ${ }^{2}$, Atsushi Ueda ${ }^{1,3}$, John W. M. Agar ${ }^{4}$, and Norihiro Itsubo ${ }^{2}$ \\ ${ }^{1}$ Department of Nephrology, Faculty of Medicine, University of Tsukuba, Japan \\ ${ }^{2}$ Faculty of Environmental and Information Studies, Tokyo City University, Japan \\ ${ }^{3}$ Department of Nephrology, Hitachi General Hospital, Japan \\ ${ }^{4}$ Department of Renal Medicine, University Hospital Geelong, Australia
}

\begin{abstract}
The health effects of climate change are becoming increasingly important; there are direct effects from heatwaves and floods, and indirect effects from the altered distribution of infectious diseases and changes in crop yield. Ironically, the healthcare system itself carries an environmental burden, contributing to environmental health impacts. Life cycle assessment is a widely accepted and well-established method that quantitatively evaluates environmental impact. Given that monetary evaluations have the potential to motivate private companies and societies to reduce greenhouse gas emissions using market mechanisms, instead of assessing the carbon footprint alone, we previously developed a life cycle impact assessment method based on an endpoint that integrates comprehensive environmental burdens into a single index - the monetary cost. Previous investigations estimated that therapy for chronic kidney disease had a significant carbon footprint in the healthcare sector. We have been aiming to investigate on the environmental impact of chronic kidney disease based on field surveys from the renal department in a hospital and several health clinics in Japan. To live sustainably, it is necessary to establish cultures, practices, and research that aims to conserve resources to provide environmentally friendly healthcare in Japan.
\end{abstract}

Key words: healthcare, carbon footprint, life cycle assessment, life cycle impact assessment, chronic dialysis

(J Rural Med 2021; 16(3): 132-138)

\section{Introduction}

Recently, human-induced climate change has been identified as the greatest global health threat ${ }^{1)}$. The temperature of the Earth is determined by the balance between energy input from the sun, and energy lost back into space. Atmospheric gases such as water vapor, carbon dioxide $\left(\mathrm{CO}_{2}\right)$, ozone, methane, and nitrous oxides are known as greenhouse gases (GHGs); these GHGs are required for photosynthesis and to warm the Earth. Industrial activities and changes to the natural landscape, such as deforestation, produce GHG

Received: September 24, 2020

Accepted: February 12, 2021

Correspondence: Kei Nagai, Department of Nephrology, Faculty of Medicine, University of Tsukuba, 1-1-1 Ten-no dai, Tsukuba, Ibaraki 305-8575, Japan

E-mail: knagai@md.tsukuba.ac.jp

This is an open-access article distributed under the terms of the Creative Commons Attribution Non-Commercial No Derivatives
(by-nc-nd) License $<\mathrm{http} / / /$ creativecommons.org/ licenses/by-nc-nd/4.0/>. emissions; these emissions have raised the average global temperature by $0.85 \%$ between 1880 and $2012^{2)}$. Experts have examined several warming scenarios, and have forecasted that the global mean surface temperature may rise between 0.3 and $4.8{ }^{\circ} \mathrm{C}$ by $2100^{3)}$. Alarmingly, global $\mathrm{CO}_{2}$ emissions are rising faster than the predicted worst-case emission scenarios ${ }^{4)}$. In 2018, the Intergovernmental Panel on Climate Change (IPCC) stated that annual global emissions must be halved by 2030 , and net-zero emissions must be achieved by 2050 to limit warming to $1.5^{\circ} \mathrm{C}^{5}$.

Alongside the higher incidence and severity of extreme weather events due to global climate change, heat stress presents a real risk of death in vulnerable populations ${ }^{6}$. Ironically, the healthcare system itself carries an environmental burden that contributes to global climate change. Healthcare activities contribute significantly to the total national $\mathrm{CO}_{2}$ emissions, although these contributions vary widely depending on the country. For example, this contribution was estimated to be $10 \%$ in the United States for 2003-20137), 7\% in Australia for 2014-2015 ${ }^{8}$, and a modest $4 \%$ in England in 20129). Subsequent international studies have carried out a global assessment of the wide-ranging 
environmental footprint of the healthcare sector ${ }^{10)}$. Studies suggest that the enhanced activity of the healthcare sector initiates an adverse feedback cycle by increasing the environmental impact of healthcare (Figure 1).

Reducing GHG emissions protects human health from the direct and indirect impacts of climate change ${ }^{11)}$. It also benefits human health through mechanisms independent of those related to modifying climate risk; these are the health co-benefits of mitigation ${ }^{12,13)}$. Human populations will grow, age, and likely become more vulnerable to climate risk. As such, there is an immediate need for action to avoid worstcase future scenarios ${ }^{11}$. This review aims to summarize the evidence linking health and environmental sustainability to help establish best practices that consider humans and the planet.

\section{Effect of Climate Change on Human Health}

The principal pathways linking climate change with health may be categorized into direct and indirect mechanisms ${ }^{11,14,15)}$. Direct risks are due to changes in the characteristics of extreme weather events and the resulting storms, floods, droughts or heatwaves. Indirect risks are mediated by the effects of climate change on ecosystems and social structure $^{11)}$. The estimated impact of climate change on human health is likely to change depending on the predicted future climate and socioeconomic scenarios ${ }^{16,17)}$. A previous study has estimated the climate-related relative risks of health effects, and the ratio of deteriorating health alongside climate change relative to that without climate change ${ }^{18)}$. These risks are shaped by social and geographic dimensions, unevenly distributed across the world, and are influenced by socioeconomic development, technology, and health service provision ${ }^{1)}$.

\section{Direct effects}

Direct effects on human health and wellbeing result from rising temperatures and subsequent changes in the frequency and intensity of storms ${ }^{19)}$, floods ${ }^{20)}$, droughts ${ }^{21)}$, and heatwaves $^{22)}$. Although societies are adapted to local climates across the world, heatwaves represent a real risk to vulnerable populations; there is a potential for significant increases in risk from extreme heat under each of the predicted climate change scenarios ${ }^{6}$. On an individual basis, tolerance to any change is diminished in individuals whose capacity for temperature homeostasis is limited by the extremes of age or dehydration ${ }^{11)}$. Collectively, there is strong evidence for a relationship between extreme high temperature and human morbidity and mortality, and heat-related mortality is rising as a result of climate change across a range of localities ${ }^{23)}$.

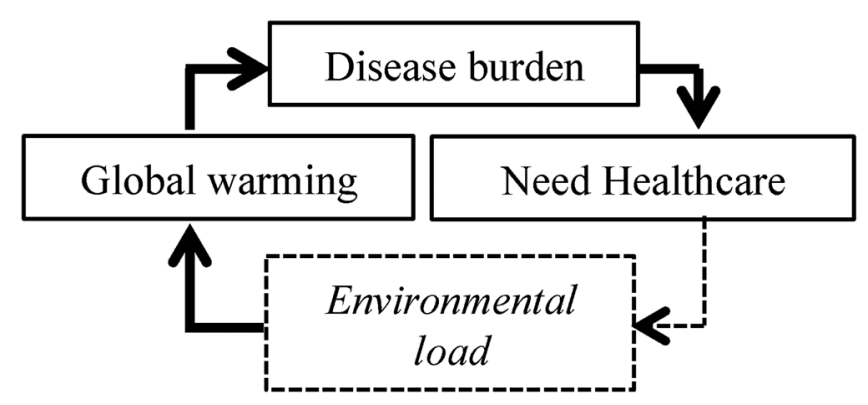

Figure 1 Cycle of climate change, disease and healthcare.

We propose the concept of a feedback cycle between climate change, an excessive disease burden, an increased need for healthcare services, and accelerated greenhouse gas emissions that increase global temperatures. Compared to the impact of environmental change on health, the impact of healthcare on the environment has received less attention.

\section{Indirect effects}

Climate conditions affect the risks associated with the transmission and distribution of diseases through vectors such as mosquitoes carrying dengue or malaria ${ }^{24}$. Changing weather patterns are also likely to affect the incidence of diseases transmitted through infected water sources ${ }^{25}$, such as hurricanes that result in the mixing of wastewater and drinking water. This creates insufficient access to clean water, potentially causing cholera ${ }^{26)}$ and typhoid fever ${ }^{27)}$. Changes in temperature, precipitation frequency, and air stagnation affect the severity of air pollution, posing significant health risks. Fine particle air pollution is estimated to be responsible for 4.2 million additional deaths globally every year, mainly due to respiratory and cardiovascular diseases $^{28)}$. Climate change has important implications for livelihood, food security, and poverty as crops and livestock have physiological limits in terms of health, productivity, and survival, including those imposed by temperature. Heat also poses significant risks to occupational health and labor productivity in areas where people work outdoors (e.g., farmers), for long hours in hot regions ${ }^{29)}$. Moreover, the higher frequency of droughts, floods, and other extreme weather events impact crops and livestock yields; this means the number of habitable areas on the planet are declining ${ }^{1,5,6)}$.

Climate change-induced migration can occur through a variety of social and political pathways. This ranges from sea level rise and coastal erosion, to changes in extreme weather, average precipitation and temperature, which reduces land availability and exacerbates food and water security issues. Although predicting the actual number of people to be affected by climate change continues to be a challenge, a large number of people will be forced to migrate by $2050^{30)}$. Climate change is considered an important factor in exacerbating the likelihood of conflict ${ }^{30)}$. Migration driven by climate change may incur potentially severe impacts on 
mental and physical health through wide-ranging and complicated mechanisms ${ }^{31,32)}$.

\section{Consequences of climate change-related health effects}

Collectively, climate change poses a clear risk to mental illness ${ }^{33,}{ }^{34)}$, malnutrition ${ }^{35)}$, allergies ${ }^{36)}$, cardiovascular diseases $^{37)}$, infectious diseases ${ }^{24,26,27,38)}$, injuries ${ }^{39)}$, respiratory diseases $^{28)}$, poisoning ${ }^{40,41)}$ and renal diseases ${ }^{42,43)}$ via complicated mechanisms; the evidence supporting this relationship has been progressively collected over time.

\section{Carbon Footprint of Healthcare}

Compared to the health impacts of environmental changes, the impact of healthcare on the environment has received less attention ${ }^{10)}$. The environmental footprint of the healthcare sector, including air, water, and soil pollution, has unintended and negative impacts on human health ${ }^{7)}$. By 2009, a global movement on planetary health had been initiated, and in 2015 the Lancet Commission on Health and Climate Change provided several recommendations ${ }^{1,11)}$, calling for: "Support for accurate quantification of the avoided burden of disease, reduced healthcare costs, and enhanced economic productivity associated with climate change mitigation". Their recommendations also noted that "these will be most effective when combined with adequate local capacity and political support to develop low-carbon healthy energy choices".

In light of these recommendations, there is an urgent need to clarify the current carbon footprint of the general and specific healthcare sectors. With increasing investment in healthcare around the world, there is considerable potential to exacerbate the harm to human health from the pollution and environmental damage from this sector ${ }^{10)}$.

\section{General healthcare sector}

The most aggressive attempt to quantify health-related GHG emissions was undertaken by the United Kingdom National Health Service (NHS). They used an estimate derived from NHS expenditure data and supplemented this with detailed data on building energy consumption and travel; the complete life cycle carbon footprint of the NHS for the 2004 calendar year was 21.3 million metric tons of $\mathrm{CO}_{2}$ equivalent $\left(\mathrm{CO}_{2} \mathrm{e}\right)$, which is approximately $3 \%$ of all emissions in England ${ }^{44)}$. Subsequently, studies at the national-scale for the United Kingdom ${ }^{45)}$, United States ${ }^{7,46)}$, Cana$\mathrm{da}^{47)}, \mathrm{Japan}^{48)}$, and Australia ${ }^{8)}$ reported that healthcare sector emissions contributed between $4 \%$ and $10 \%$ of total GHG emissions in these countries; these were largely based on NHS expenditure data. Recently, international collaborative studies have found that healthcare causes global environmental impacts ${ }^{10,49)}$. Researchers used a global supply-chain database containing detailed information on healthcare sectors and quantified the direct and indirect environmental damage driven by the demand for healthcare ${ }^{10)}$. The study revealed that the global environmental burden from healthcare was between $1 \%$ and $5 \%$ of the total global burden, and accounts for more than $5 \%$ of the national burden in some countries $^{10)}$. In most countries, the healthcare sector had the largest carbon footprint of the service sectors, and was comparable in size to the food sector ${ }^{49}$.

\section{Surgical sector and intensive care}

Among healthcare services, the contribution of surgical procedures and intensive care on the carbon footprint have been considered. A determination of the carbon footprint of three academic quaternary-care hospitals in Canada, the United Kingdom and United States revealed that surgical operating suites emitted 3.2 to 5.1 million $\mathrm{kg}$ of $\mathrm{CO}_{2} \mathrm{e}$ over $1 \mathrm{y}^{50)}$. Interestingly, the use of anesthetic gases and energy consumption substantially contributed to the overall carbon footprint of the healthcare sector. Another report from a university hospital revealed that the carbon footprint for one cataract operation was $181.8 \mathrm{~kg}$ of $\mathrm{CO}_{2} \mathrm{e}^{51)}$. Building and energy use was estimated to account for $36.1 \%$ of overall emissions, while travel and procurement (including medical equipment) was estimated to be $10.1 \%$, and $53.8 \%$, respectively ${ }^{51)}$. Comparing the surgical treatment of gastric reflux with medical management, the initial carbon footprint from surgery was $1,081 \mathrm{~kg}$ of $\mathrm{CO}_{2}$ e per patient ${ }^{52}$. This is nearly seven times greater than the footprint of medical management; however, subsequent emissions from continuing treatment were much lower for surgical patients (30 versus $100 \mathrm{~kg}$ of $\left.\mathrm{CO}_{2} \mathrm{e}\right)$. A review of 150 procedures using laparotomy, conventional laparoscopy or robotically associated laparoscopy, revealed that the total carbon footprint per patient was $22.7,29.2$, and $40.3 \mathrm{~kg}$ of $\mathrm{CO}_{2} \mathrm{e}$, respectively ${ }^{53)}$. In intensive care units, the daily carbon footprint was $178 \mathrm{~kg}$ of $\mathrm{CO}_{2}$ e per patient with septic shock in the United States ${ }^{54}$. Such estimates from a bottom-up inventory of items associated with intense GHG emissions are important to promote environmentally friendly healthcare for specific medical conditions.

\section{Renal treatment sector}

Maintenance hemodialysis (HD) is a major therapy used to save the lives of patients with end-stage renal disease. HD programs have a particularly large carbon footprint, with recurrent, per capita resource consumption and waste generation profiles that are disproportionately high compared with most other medical therapies ${ }^{55-57)}$. Patients undergoing conventional in-center HD, with a $4 \mathrm{~h}$ thriceweekly regimen, were estimated to use approximately 500 L of water per treatment, based on a previous survey ${ }^{58}$. Moreover, this therapy was responsible for a considerable 
amount of waste generation and travel distance of patients and staff ${ }^{55,58)}$. As a result, annual emissions were estimated at 3.8 and 10.2 tons of $\mathrm{CO}_{2}$ e per patient in the United Kingdom and Australia, respectively ${ }^{56)}$; this is more than twothirds of the estimated national mean annual per capita $\mathrm{CO}_{2}$ emissions of 15.4 tons. The largest share of carbon emissions originated from pharmaceuticals $(37.5 \%)$ and medical equipment $(23.5 \%)^{56)}$, which was consistent with findings in other sectors ${ }^{51)}$. Unfortunately, despite their apparent large collective carbon footprint, there is very little data available on the life cycle impacts of individual pharmaceutical compounds or devices ${ }^{59}$. Beyond carbon emissions, more comprehensive life cycle analysis is also required to identify the broader environmental impacts of pharmaceuticals and devices (e.g., pollution and resource depletion during production) ${ }^{55)}$.

\section{Life Cycle Assessment to Determine Precise Local Environmental Impacts and Damage}

Life cycle assessment (LCA) is a widely accepted and well-established method to quantitatively evaluate environmental processes and products ${ }^{60-62)}$. During the manufacturing stage, environmental impacts are assessed from raw material extraction and processing (cradle), the manufacture, distribution, and use, to the recycling or final disposal stages (grave). For example, in terms of hemodialysis treatments, the distribution of the dialysate powder concentrate from a factory to a dialysis unit appears to have a lower environmental load than liquid concentrate. However, it is possible that the manufacturing of highly concentrated powders requires a large amount of energy; as such, it is still unclear whether the powder or liquid concentrate is suitable for environment-friendly HD. Although there is little scientific evidence available on LCA in dialysis technology beyond the carbon footprint study, several LCA methods have recently been developed, and may be applied to the renal treatment sector.

National-scale studies for the United Kingdom ${ }^{45}$, the United States $^{7,46)}$, Canada ${ }^{47)}$, Japan ${ }^{48)}$, and Australia ${ }^{8)}$ have used environmentally extended input-output (EEIO) modeling to show that healthcare sector emissions contribute to the total national emissions in these countries. EEIO models have been widely used since the $1970 \mathrm{~s}^{63}$, and underpin consumption-based accounting of emissions ${ }^{64)}$. An important advantage of using EEIO modeling is that healthcare sector emissions are estimated on a life cycle basis. This means that estimates account for electricity, transportation and pharmaceuticals ${ }^{65)}$. Each country records emission inventories, monetary input-output tables, and health expenditure data. As such, differences in the assessment of emissions need to be corrected and used in a global scope with a multi-region input-output (MRIO) that covers more than one country ${ }^{49}$. Recent worldwide research has utilized powerful models that include 14,847 country-sectors from 189 countries $^{10)}$.

Although there is an urgent need to assess the deteriorating health, impacts, and environmental burden of the healthcare sector, most existing methods do not provide detailed information on the extent of impact on humans and the environment ${ }^{66)}$. This prompted the development of a methodology using the results of damage assessment called life cycle impact assessment (LCIA), which has rapidly attracted attention. The Life Cycle Impact Assessment Method based on Endpoint Modeling (LIME), was developed in Japan and published in 200567); in 2015, it was updated to version 3 (LIME-3). This LCIA uses impact categories such as midpoints (e.g., air and water pollution) and endpoints (e.g., human health and biodiversity), and integrates these outcomes simply, through the use of a single index. Remarkably, LIME can evaluate the monetary index with the potential to put pressure on companies and societies to reduce GHGs using market mechanisms ${ }^{68)}$ (Figure 2).

\section{Future Direction: An On-going Field Survey of the Renal Sector}

An important topic for future research is the connection between the healthcare carbon footprint, healthcare performance, and health outcomes ${ }^{49,69)}$. As previously discussed and well-summarized in reviews ${ }^{57,58)}$, chronic dialysis therapy for end-stage renal disease is resource-heavy. This is particularly the case in remote areas because of the transportation of patients and medical staff, and the large amounts of pharmaceuticals and devices required. The delivery of dialysis therapy also differs between countries ${ }^{70)}$. From the environmental conservation perspective, home dialysis therapy is more popular because of geographic and water supply issues; this has been investigated more in Australia and the United Kingdom than in Japan ${ }^{57,58,71)}$. This provided the basis to examine the current reality of dialysis therapy in Japan, focusing on environmental problems in order to develop future planet-friendly therapeutics for renal disease.

There is also a need for broader surveying of environmental attitude, knowledge, and practice patterns around the world; this has been undertaken in the United Kingdom and Australia ${ }^{15}{ }^{72}$. Following this initiative, we established a patient-based cohort with end-stage renal disease and regional surveillance for patients and medical staff in a hospital and several health clinics in Japan (unpublished). To the best of our knowledge, this is the first attempt at an environmentally-themed research in the renal sector in Japan. There has also been an investigation into the health consciousness and pro-environmental behavior of non-specific health professionals in a large hospital in $\operatorname{Japan}^{73)}$. We aim to establish 


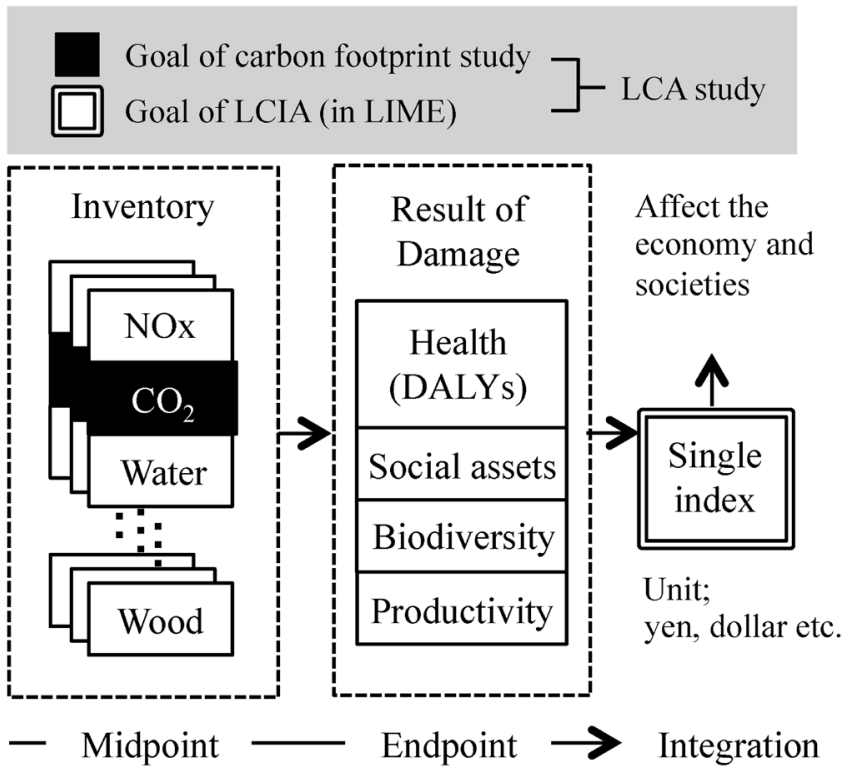

Figure 2 Concise diagram of life cycle assessment and life cycle impact assessment.

Most life cycle assessment studies have quantified $\mathrm{CO}_{2}$ emissions relating to various human activities, including healthcare. Beyond midpoint investigations such as carbon footprint counting, life cycle impact assessment depicts the actual impacts on humans and natural ecosystems based on human activity and industry. Quantification of detrimental health effects, social asset loss, destruction of biodiversity, and reduction in productivity such as photosynthesis are integrated into a single index to clearly show the environmental burden of human activity. Monetary evaluations (e. g., yen and dollar) have the potential to motivate private companies and societies to reduce greenhouse gas emissions using market mechanisms. Abbreviations: LCA, life cycle assessment; LCIA, life cycle impact assessment; LIME, life cycle impact assessment method based on endpoint modeling; DALYs, disability-adjusted life years. more relevant basic units of medical procedures and procurement for LCIA, and ultimately develop an optimal solution for mitigating climate change and maintaining human health and society. Additionally, popularizing a resource conservation culture, practice, and research is necessary to achieve environmentally friendly healthcare in Japan, given its high healthcare and environmental burden.

\section{Conclusion}

The medical community is positioned at the forefront of responding to the health impacts of climate change. The health profession has the ability and the responsibility to act as public health advocates by communicating the threats and opportunities to the public and policy makers, and ensuring that climate change is understood as being central to human wellbeing ${ }^{14,33}$. Beyond quantifying the carbon footprint, the recently developed LCIA should be put into practice and used to evaluate the environmental burden of healthcare. On-site field surveys are also beneficial towards establishing bottom-up inventory data regarding healthcare. This data should focus on the appropriate sector and evaluate the carbon footprint, and impacts to human health and natural ecosystems.

\section{Acknowledgements}

This article was supported in part by the Japan Society of the Promotion of Science (JSPS) grant no. 18KK0431 and the Japanese Association of Dialysis Physicians grant no. 2019-1. We thank Dr. Kentaro Nakajima for his contribution to data collection.

\section{References}

1. Costello A, Abbas M, Allen A, et al. Managing the health effects of climate change: Lancet and University College London Institute for Global Health Commission. Lancet 2009; 373: 1693-1733. [Medline] [CrossRef]

2. Stocker TF, Qin D, Plattner GK, et al. Intergocernmental Panel on Climate Change. Summary for Policymakers. Climate change 2013: the physical science basis contribution of Working Group I to the Fifth Assessment Report of the Intergovernmental Panel on Climate Change. Cambridge, UK and New York, NY, USA: Cambridge University Press; 2013, 1-30.

3. Intergocernmental Panel on Climate Change. AR5 Synthesis Report: Climate Change 2014. 2015.

4. Pielke R Jr, Wigley T, Green C. Dangerous assumptions. Nature 2008; 452: 531-532. [Medline] [CrossRef]

5. Intergocernmental Panel on Climate Change (IPCC) Global warming of $1 \cdot 5^{\circ} \mathrm{C}$. An IPCC Special Report on the impacts of global warming of $1 \cdot 5^{\circ} \mathrm{C}$ above preindustrial levels and related global greenhouse gas emission pathways, in the context of strengthening the global response to the threat of climate change. Geneve: World Meteorogical Organization; 2018.

6. Patz JA, Campbell-Lendrum D, Holloway T, et al. Impact of regional climate change on human health. Nature 2005; 438: 310-317. [Medline] [CrossRef]

7. Eckelman MJ, Sherman J. Environmental impacts of the U.S. health care system and effects on public health. PLoS One 2016; 11: e0157014. [Medline] [CrossRef]

8. Malik A, Lenzen M, McAlister S, et al. The carbon footprint of Australian health care. Lancet Planet Health 2018; 2: e27-e35. [Medline] [CrossRef]

9. Sustainable Development Unit NHS Carbon footprint update for the NHS in England 2015. https://www.sduhealth.org.uk/policy-strategy/reporting/nhscarbon-footprint.aspx.

10. Lenzen M, Malik A, Li M, et al. The environmental footprint of health care: a global assessment. Lancet Planet Health 2020; 4: e271-e279. [Medline] 
[CrossRef]

11. Watts N, Adger WN, Agnolucci P, et al. Health and climate change: policy responses to protect public health. Lancet 2015; 386: 1861-1914. [Medline] [CrossRef]

12. World Health Organization (WHO) Health in the Green Economy. Geneve: WHO; 2011.

13. Woodward A, Smith KR, Campbell-Lendrum D, et al. Climate change and health: on the latest IPCC report. Lancet 2014; 383: 1185-1189. [Medline] [CrossRef]

14. Barraclough KA, Blashki GA, Holt SG, et al. Climate change and kidney disease-threats and opportunities. Kidney Int 2017; 92: 526-530. [Medline] [CrossRef]

15. Barraclough KA, Gleeson A, Holt SG, et al. Green dialysis survey: establishing a baseline for environmental sustainability across dialysis facilities in Victoria, Australia. Nephrology (Carlton) 2019; 24: 88-93. [Medline] [CrossRef]

16. Hales SKR, Lloyd S, Campbell-Lendrum D. Quantitative risk assessment of the effects of climate change on selected causes of death, 2030s and 2050s. Geneva: World Health Organization (WHO); 2014.

17. Tang LL, Honda Y, Hasegawa T, et al. Estimating huma health damage factors related to $\mathrm{CO}_{2}$ emissions by considering updated climate-relate relative risks. Int J Life Cycle Assess 2019; 24: 1118-1128. [CrossRef]

18. Ezzati MLA, Rodgers A, Murray CJL. Comparative quantification of health risks. Global and regional burden of diseases attributable to selected major risk factors. Geneva: World Health Organization; 2004.

19. Shultz JM, Shepherd JM, Kelman I, et al. Mitigating tropical cyclone risks and health consequences: urgencies and innovations. Lancet Planet Health 2018; 2: e103-e104. [Medline] [CrossRef]

20. The Lancet Extreme rain, flooding, and health. Lancet 2017; 390: 1005. [Medline] [CrossRef]

21. Berman JD, Ebisu K, Peng RD, et al. Drought and the risk of hospital admissions and mortality in older adults in western USA from 2000 to 2013: a retrospective study. Lancet Planet Health 2017; 1: e17-e25. [Medline] [CrossRef]

22. The Lancet Heatwaves and health. Lancet 2018; 392: 359. [Medline] [CrossRef]

23. Aström C, Orru H, Rocklöv J, et al. Heat-related respiratory hospital admissions in Europe in a changing climate: a health impact assessment. BMJ Open 2013; 3: e001842. [Medline] [CrossRef]

24. World Health Organization (WHO) World malaria report. Geneve: WHO; 2012.

25. Lipp EK, Huq A, Colwell RR. Effects of global climate on infectious disease: the cholera model. Clin Microbiol Rev 2002; 15: 757-770. [Medline] [CrossRef]

26. Lessler J, Moore SM, Luquero FJ, et al. Mapping the burden of cholera in sub-Saharan Africa and implications for control: an analysis of data across geographical scales. Lancet 2018; 391: 1908-1915. [Medline] [CrossRef]

27. GBD 2017 Typhoid and Paratyphoid Collaborators The global burden of typhoid and paratyphoid fevers: a systematic analysis for the Global Burden of Disease Study 2017. Lancet Infect Dis 2019; 19: 369-381. [Medline] [CrossRef]

28. World Health Organization (WHO) WHO Global Ambient Air Quality Database (update 2018) 2016 [cited 2020]. https://www.who.int/health-topics/airpollution\#tab=tab_1.

29. Kjellstrom T. Climate change, direct heat exposure, health and well-being in low and middle-income countries. Glob Health Action 2009; 2:. [Medline] [CrossRef]

30. Brown O. Migration and climate change. Geneva: International Organization for Migration; 2008.

31. Gleick PH. Water, drought, climate change, and conflict in Syria. Weather Clim Soc 2014; 6: 331-340. [CrossRef]

32. McMichael C, Barnett J, McMichael AJ. An ill wind? Climate change, migration, and health. Environ Health Perspect 2012; 120: 646-654. [Medline] [CrossRef]

33. Watts N, Amann M, Ayeb-Karlsson S, et al. The Lancet Countdown on health and climate change: from 25 years of inaction to a global transformation for public health. Lancet 2018; 391: 581-630. [Medline] [CrossRef]

34. Berry HL, Waite T, Dear KBG, et al. The case for systems thinking about climate change and mental health. Nat Clim Chang 2018; 8: 282-290. [CrossRef]

35. Schmidhuber J, Tubiello FN. Global food security under climate change. Proc Natl Acad Sci USA 2007; 104: 19703-19708. [Medline] [CrossRef]

36. D'Amato G, Akdis CA. Global warming, climate change, air pollution and allergies. Allergy 2020; 75: $2158-2160$ [Online ahead of print]. [Medline] [CrossRef]

37. Dominguez-Rodriguez A, Rodríguez S, Hernández-Vaquero D. Air pollution is intimately linked to global climate change: change in Cardiovascular Disease Statistics 2019. Eur Heart J 2020; 41: 2601. [Medline]

38. Patz JA, Epstein PR, Burke TA, et al. Global climate change and emerging infectious diseases. JAMA 1996; 275: 217-223. [Medline] [CrossRef]

39. Lee H, Myung W, Kim H, et al. Association between ambient temperature and injury by intentions and mechanisms: a case-crossover design with a distributed lag nonlinear model. Sci Total Environ 2020; 746: 141261. [Medline] [CrossRef]

40. Botana LM. Toxicological perspective on climate change: aquatic toxins. Chem Res Toxicol 2016; 29: 619-625. [Medline] [CrossRef]

41. Lake IR. Food-borne disease and climate change in the United Kingdom. Environ Health 2017; 16(Suppl 1): 117. [Medline] [CrossRef]

42. Glaser J, Lemery J, Rajagopalan B, et al. Climate change and the emergent epidemic of CKD from heat stress in rural communities: the case for heat stress nephropathy. Clin J Am Soc Nephrol 2016; 11: 1472-1483. [Medline] [CrossRef]

43. McMichael AJ. Globalization, climate change, and human health. N Engl J Med 2013; 368: 1335-1343. [Medline] [CrossRef]

44. Sustainable Development Commission, Stockholm Environment Institute (SEI) NHS England Carbon Emissions Carbon Footprinting Report. London, UK. Sustainable Development Commission; 2008

45. Pencheon D. Developing a sustainable health care system: the United Kingdom experience. Med J Aust 2018; 208: 284-285. [Medline] [CrossRef]

46. Chung JW, Meltzer DO. Estimate of the carbon footprint of the US health care sector. JAMA 2009; 302: 1970-1972. [Medline] [CrossRef]

47. Eckelman MJ, Sherman JD, MacNeill AJ. Life cycle environmental emissions and health damages from the Canadian healthcare system: an economicenvironmental-epidemiological analysis. PLoS Med 2018; 15: e1002623. [Medline] [CrossRef]

48. Nansai K, Fry J, Arunima M, et al. Carbon footprint of Japanese health care services from 2011 to 2015. Resour Conserv Recycling 2020; 152 : 104525. [CrossRef]

49. Pichler PP, Jaccard IS, Weisz U, et al. International comparison of health care carbon footprints. Environ Res Lett 2019; 14: 064004. [CrossRef]

50. MacNeill AJ, Lillywhite R, Brown CJ. The impact of surgery on global climate: a carbon footprinting study of operating theatres in three health systems. Lancet Planet Health 2017; 1: e381-e388. [Medline] [CrossRef]

51. Morris DS, Wright T, Somner JE, et al. The carbon footprint of cataract surgery. Eye (Lond) 2013; 27: 495-501. [Medline] [CrossRef] 
52. Gatenby PA. Modelling the carbon footprint of reflux control. Int J Surg 2011; 9: 72-74. [Medline] [CrossRef]

53. Woods DL, McAndrew T, Nevadunsky N, et al. Carbon footprint of robotically-assisted laparoscopy, laparoscopy and laparotomy: a comparison. Int J Med Robot 2015; 11: 406-412. [Medline] [CrossRef]

54. McGain F, Burnham JP, Lau R, et al. The carbon footprint of treating patients with septic shock in the intensive care unit. Crit Care Resusc 2018; 20: 304-312. [Medline]

55. Barraclough KA, Agar JWM. Green nephrology. Nat Rev Nephrol 2020; 16: 257-268. [Medline] [CrossRef]

56. Lim AE, Perkins A, Agar JW. The carbon footprint of an Australian satellite haemodialysis unit. Aust Health Rev 2013; 37: 369-374. [Medline] [CrossRef]

57. Connor A, Lillywhite R, Cooke MW. The carbon footprints of home and in-center maintenance hemodialysis in the United Kingdom. Hemodial Int 2011; 15: 39-51. [Medline] [CrossRef]

58. Agar JW. Green dialysis: the environmental challenges ahead. Semin Dial 2015; 28: 186-192. [Medline] [CrossRef]

59. McAlister S, Ou Y, Neff E, et al. The Environmental footprint of morphine: a life cycle assessment from opium poppy farming to the packaged drug. BMJ Open 2016; 6: e013302. [Medline] [CrossRef]

60. Piccoli GB, Nazha M, Ferraresi M, et al. Eco-dialysis: the financial and ecological costs of dialysis waste products: is a 'cradle-to-cradle' model feasible for planet-friendly haemodialysis waste management? Nephrol Dial Transplant 2015; 30: 1018-1027. [Medline] [CrossRef]

61. Piccoli GB, Cupisti A, Aucella F, et al. On the Behalf of Conservative treatment, Physical activity and Peritoneal dialysis project groups of the Italian Society of Nephrology Green nephrology and eco-dialysis: a position statement by the Italian Society of Nephrology. J Nephrol 2020; 33: 681-698. [Medline] [CrossRef]

62. Commission Recommendation of 9 April 2013 on the use of common methods to measure and communicate the life cycle environmental performance of products and organisations. Official Journal of the European Union. 2013. https://op.europa.eu/en/publication-detail/-/publication/93cb8358-b80d-11e2ab01-01aa75ed71a1/language-en.

63. Leontief W. Environmental repercussions and the economic structure: an input-output approach. Rev Econ Stat 1970; 52: 262-271. [CrossRef]

64. Hertwich EG, Peters GP. Carbon footprint of nations: a global, trade-linked analysis. Environ Sci Technol 2009; 43: 6414-6420. [Medline] [CrossRef]

65. Watts N, Amann M, Arnell N, et al. The 2019 report of The Lancet Countdown on health and climate change: ensuring that the health of a child born today is not defined by a changing climate. Lancet 2019; 394: 1836-1878. [Medline] [CrossRef]

66. Matsuno Y, Itsubo N, Hondo H. LCA in Japan in the twenty-first century. Int J Life Cycle Assess 2013; 18: 278-284. [CrossRef]

67. Itsubo N, Inaba A. LIME, a Life Cycle Environmental Impact Assessment Method—assessment methods and databases for LCA. Japan Environmental Management Association for Industry; 2005.

68. Inaba A, Itsubo N. Preface. Int J Life Cycle Assess 2018; 23: 2271-2275. [CrossRef]

69. Haines A. Health co-benefits of climate action. Lancet Planet Health 2017; 1: e4-e5. [Medline] [CrossRef]

70. Goodkin DA, Bragg-Gresham JL, Koenig KG, et al. Association of comorbid conditions and mortality in hemodialysis patients in Europe, Japan, and the United States: the Dialysis Outcomes and Practice Patterns Study (DOPPS). J Am Soc Nephrol 2003; 14: 3270-3277. [Medline] [CrossRef]

71. Connor A, Lillywhite R, Cooke MW. The carbon footprint of a renal service in the United Kingdom. QJM 2010; 103: 965-975. [Medline] [CrossRef]

72. Connor A, Mortimer F. The green nephrology survey of sustainability in renal units in England, Scotland and Wales. J Ren Care 2010; 36: 153-160. [Medline] [CrossRef]

73. Shimoda A, Hayashi H, Sussman D, et al. Our health, our planet: a cross-sectional analysis on the association between health consciousness and proenvironmental behavior among health professionals. Int J Environ Health Res 2020; 30: 63-74. [Medline] [CrossRef] 